\title{
A Study on the Impact of Environmental Education on Individuals' Behaviors Concerning Recycled Water Reuse
}

\author{
Hanliang Fu \\ School of Management, Xi'an University of Architecture and Technology, Xi'an 710055, CHINA \\ Xiaojun Liu \\ School of Management, Xi'an University of Architecture and Technology, Xi'an 710055, CHINA
}

Received 6 May 2017 • Revised 25 August 2017 - Accepted 25 September 2017

\begin{abstract}
In order to verify whether environmental education can play guiding role among the individuals in terms of the reuse of recycled water, and to further confirm its mechanism of action, a structural equation model was established in this study regarding to the influence of knowledge about recycled water on acceptability of recycled water. Besides, a survey was made among 714 individuals. The structural equation model revealed that high levels of knowledge about recycled water stimulate individuals' trust in water authorities, and reduce their perceived risk of recycled water. More specially, knowledge about recycled water was reported to be a significant predictor of individuals' acceptability of recycled water. Individuals' high levels knowledge about recycled water can affect their acceptability of recycled water indirectly through two different ways, while high levels knowledge about recycled water can reduce the individuals' perceived risk of recycled water, so it could increase their acceptability of recycled water indirectly. Another influence path is that high levels knowledge about recycled water could reduce individuals' perceived risk of recycled water by improving their trust in the water authorities, and ultimately improve their acceptability of recycled water. In this paper, it has proved that environmental education has significance guiding effect on individuals in terms of the use of recycled water, and provided a clue as how does environmental education affects individuals' behavior to use recycled water.
\end{abstract}

Keywords: environmental education, recycled water reuse, structural equation modeling

\section{INTRODUCTION}

With the socio-economic development, the growth of population and the improvement of people's demand for quality of life, human activities are sharply deteriorating the consumption of natural resources and environmental pollution (Bogardi 2012, Chen 2017.). Thus, human behaviors have become the most important factor affecting natural environment (Pahl-Wostl 2013). The damage and the impact exceed the earth's ecological carrying capacity, which results in irreversible damage to the ecological environment. At the same time, due to climate change and the sustainable development of human society, this contradiction is getting fiercer so the issue that the deterioration of the ecological environment restricts social and economic development has become a major problem that all mankind must face in the 21st century.

(C) Authors. Terms and conditions of Creative Commons Attribution 4.0 International (CC BY 4.0) apply. Correspondence: Hanliang Fu, School of Management, Xi'an University of Architecture and Technology, Xi'an 710055, China. 


\section{Contribution of this paper to the literature}

- This research has proved that environmental education has significance guiding role on individuals in terms of the use of recycled water.

- This research has provided a clue as how does environmental education affects individuals' behavior to use recycled water.

Environmental education enables people to understand the knowledge of environmental protection and to develop pro-environmental behaviors, which is significant for mitigating the current global environmental problems (Teksoz 2012). The term "environmental education" originates from a meeting held by the International Union for Conservation of Nature in Paris, France, in 1948. During the decades when the concept of environmental education was first introduced, environmental education is generally seen as a synonym for environmental education. Until the 1970s, with the deterioration of environmental pollution problems and human concern for environmental issues, environmental education was formally identified as an independent branch of the discipline. The Stockholm Conference on the Human Environment and the Tbilisi Intergovernmental Conference on Environmental Education, which were held in 1972 and 1977 respectively, culminated international environmental education. People have gradually formed a consensus on the purpose of environmental education, that is, some citizens who understand and care about the ecological environment and its related issues are cultivated so that they have the ability to solve current ecological problems and prevent new ones (Roczen 2016). However, since different specific industries have their own characteristics, what effects environmental education will produce and how it produces these effects are still questions to be studied in these different areas.

Water shortage is undoubtedly one of the common problems faced by mankind in the 21st century. The development of recycled water reuse has become an effective means to deal with this problem because recycled water can be used as a substitute for natural water resources. The production and use of recycled water, however, involves a number of complex links, such as sewage collection, sewage disposal and recycled water transport, which are unfamiliar to the majority of the population. Nonetheless, due to the limited cognition of resources, it is of great difficulty for individuals to fully understand recycled water reuse in most cases. Therefore, it is easy for some folks to be caught in a negative or wrong understanding concerning the perception for recycled water (Chen 2015), or even they preconceive that recycled water is unsafe (Rozin 2015). It is probably the most effective way of overcoming this problem to strengthen the environmental education for residents and to popularize knowledge of recycled water reuse (Liefländer 2015). Therefore, the potential impact of environmental education on residents' behaviors about recycled water reuse is taken as the research object, the effect is verified and the path is explored.

\section{RESEARCH METHODS AND HYPOTHESES}

\section{Research Methods}

To obtain the data needed, this research takes the authoritative data of the population distribution in the administrative regions of $\mathrm{Xi}^{\prime}$ an in the sixth national census as the basis for the layered random sampling survey. The survey is made in ten distracts and 3 counties in $\mathrm{Xi}^{\prime}$ an. In the early period, the 10 surveyors were trained to know about relevant fundamental knowledge on survey. And from September 16 to October 16, 2016, the survey was conducted in the streets, central squares, shopping malls and parks randomly selected from all the districts and counties. And after, each participant was presented a beautiful gift for souvenir.

This research, based on the authoritative data of the population distribution in the administrative regions of $\mathrm{Xi}^{\prime}$ an in the sixth national census, makes random layered survey in 10 districts and 3 counties. Altogether 714 questionnaires were distributed and 584 valid questionnaires were retrieved, with a validity of $82 \%$. The percentage of questionnaire distribution of different districts roughly equals to that of the population. See specific questionnaire data in Table 1. 
Table 1. Questionnaire data

\begin{tabular}{|c|c|c|c|c|c|c|}
\hline District/county & $\begin{array}{c}\text { Questionnaire } \\
\text { validity }\end{array}$ & $\begin{array}{c}\text { Valid } \\
\text { Questionnaires }\end{array}$ & $\begin{array}{c}\text { Invalid } \\
\text { questionnaires }\end{array}$ & $\begin{array}{c}\text { The percentage } \\
\text { of valid } \\
\text { questionnaires }\end{array}$ & $\begin{array}{l}\text { District } \\
\text { population } \\
\text { (persons) }\end{array}$ & $\begin{array}{c}\text { The } \\
\text { percentage } \\
\text { of the district } \\
\text { population }\end{array}$ \\
\hline Yanta District & 0.82 & 86 & 19 & 0.15 & 1178529 & 0.14 \\
\hline $\begin{array}{l}\text { Xincheng } \\
\text { District }\end{array}$ & 0.89 & 64 & 8 & 0.11 & 589739 & 0.07 \\
\hline Zhouzhi County & 0.84 & 41 & 8 & 0.07 & 562768 & 0.07 \\
\hline Yanliang District & 0.89 & 24 & 3 & 0.04 & 278604 & 0.03 \\
\hline Baqiao District & 0.88 & 42 & 6 & 0.07 & 595124 & 0.07 \\
\hline $\begin{array}{l}\text { Chang'an } \\
\text { District }\end{array}$ & 0.84 & 53 & 10 & 0.09 & 1083285 & 0.13 \\
\hline Weiyang District & 0.82 & 59 & 13 & 0.10 & 806811 & 0.10 \\
\hline Gaoling District & 0.68 & 17 & 8 & 0.03 & 333477 & 0.04 \\
\hline Lantian County & 0.84 & 37 & 7 & 0.06 & 514026 & 0.06 \\
\hline Hu County & 0.78 & 42 & 12 & 0.07 & 556377 & 0.07 \\
\hline Lintong District & 0.85 & 45 & 8 & 0.08 & 655874 & 0.08 \\
\hline Lianhu District & 0.69 & 41 & 18 & 0.07 & 698513 & 0.08 \\
\hline Beilin District & 0.77 & 33 & 10 & 0.06 & 614710 & 0.07 \\
\hline \multirow{2}{*}{ Total } & \multirow{2}{*}{0.82} & 584 & 130 & \multirow{2}{*}{1} & \multirow{2}{*}{8467837} & \multirow{2}{*}{1} \\
\hline & & Total questiol & nnaires : 714 & & & \\
\hline
\end{tabular}

Note: The population data is from the sixth national census o State Council census in 2010

Table 2. The basic information of the participants

\begin{tabular}{lcc}
\hline Variables & Variable description & Total \\
\hline \multirow{2}{*}{ Age } & 43 and above & 120 \\
\cline { 2 - 3 } Gender & Under 43 & 454 \\
\hline \multirow{2}{*}{ Educational background } & Male & 127 \\
\cline { 2 - 3 } & Female & 447 \\
\cline { 2 - 3 } & Bachelor degree or above & 301 \\
\cline { 2 - 3 } & Others & 280 \\
\hline
\end{tabular}

The basic information of the participants is shown in Table 2.

The red dot in the map is the survey location of the questionnaire, as shown in Figure 1. 

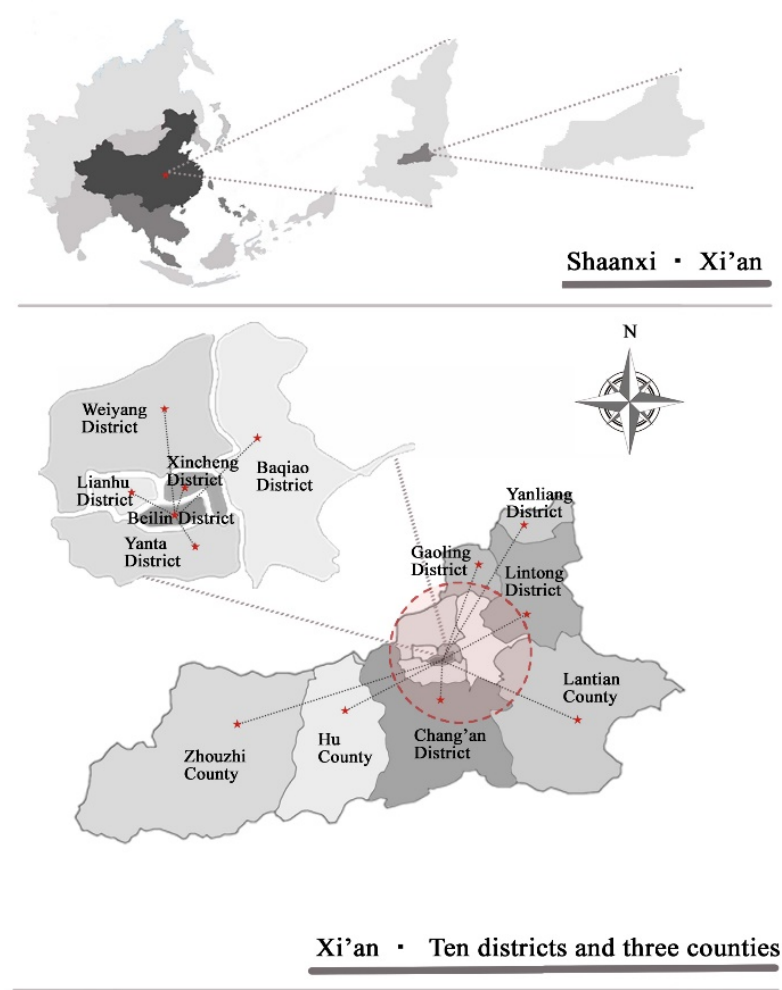

Figure 1. The survey location distribution map

\section{Variables Definition}

In the process of questionnaire design, in order to improve the validity and reliability of the questionnaire as much as possible, some classic relevant questionnaires or others successfully applied in related studies were referred and this questionnaire adopted in this study was modified in line with the characteristics of this research field, with The Likert 7 metric for the measurement of variables.

(1) Acceptability (ACC) of Recycled Water. In selecting the measurement indicators of residents' ACC, the classification of urban recycled water is referred and finally five kinds of urban miscellaneous uses of recycled water, such as residential flushing, urban road sprinkling, firefighting, residential community greening, and car washing are selected as the measurement indicator for it is closely related to the urban residents' daily lives and easy to be understood by them.

(2) Perceived Risk of Recycled Water (PR, Perceived Risk of Recycled Water). According to Sara's summary of residents' anxiety type about recycled water reuse, it can be seen that residents' concerns about recycled water reuse are mainly about not only the health risks that recycled water reuse may bring to themselves and their family members but also the impact on the local environment. Thus, this section focuses on investigating residents' risk perception for recycled water reuse from these two aspects (Ross, 2014; Lin, 2017). In order to simplify the calculation of the directness of each potential variable, the data $x^{\prime}=8-x$ is adjusted after the risk-perception facet data of recycled water reuse is substituted into the forward data direction of the model, if the original data is $x$.

(3) Trust in Water Authorities (TIWA, Trust in Water Authorities). The trust in the water authorities represents the trust in water sectors from three aspects, providing residents with reliable renewable water capacity, the original intention, and offering residents' safety information on recycled water 
(Jeffrey 2003; Hurlimann 2007). Therefore, this part of the research questionnaire mainly aims to measure residents' trust degree in water authorities from the above three aspects.

(4) Knowledge about Recycled Water (KARW, Knowledge about Recycled Water). This section aims at understanding residents' knowledge about recycled water reuse by measuring residents' knowledge about sources, processes and quality of recycled water (Ross 2014).

\section{Research Hypotheses}

A related study in the field of social psychology has found that these factors whether risk is visible, whether participants in risk are voluntary, and whether they are familiar with risk exert significant influences on residents' risk perception (Otway 1982). Residents are likely to fear something less familiar. At present, the recycled water reuse in China is in the early stage of promotion so residents' knowledge of recycled water reuse is very limited and participants are passive or even involuntary. Therefore, residents' knowledge may be an important factor influencing their risk perception at this phase. In addition, among many studies on government trust, the degree of government information disclosure has been taken seriously as another key factor. The consensus is that improving the degree of government information disclosure in operation enables residents to effectively enhance their confidence in the government. As for recycled water reuse industry, the current promotion in China to a large extent depends on government power, and an index, residents' knowledge of recycled water reuse is also dependent on the extent of relevant government information disclosure. Therefore, this index can reflect the water authorities' information disclosure degree in terms of recycled water reuse and residents' knowledge about recycled water reuse will exert a positive impact on their trust degree in water authorities. A large number of related research literature suggest that residents' risk perception degree for recycled water reuse and their trust degree in water authorities are seen as important factors influencing public willingness to accept recycled water reuse (Siegrist 2010). On this basis, the research hypotheses are put forward in this paper.

Hypothesis 1: Residents' knowledge about recycled water reuse will indirectly produce a positive effect on their willingness to receive it by influencing their trust degree in the water authorities.

Hypothesis 2: Residents' knowledge about recycled water reuse will indirectly exert a positive effect on their willingness to receive it via influencing their risk perception for recycled water reuse.

Hypothesis 3: Residents' knowledge about recycled water reuse will indirectly affect their willingness to receive it in an active way by means of influencing their trust degree in the water authorities and their risk perception for recycled water reuse.

\section{DATA ANALYSIS}

On the advice of Bentler, in order to ensure the credibility of the structural equation model, the samples should be randomly divided into two parts, one for the development of the model and the other for the repeated validation of the model (Bentler 1980). Therefore, in this part, the 584 samples gotten through stratified random sampling are randomly divided into two samples in each layer to ensure that the samples are randomly equalized in the case of keeping stratification ratio unchanged and meanwhile to avoid regional samples or regional factors' interfering in research results. Finally, 292 samples are used to develop the model, and 292 samples are used for model repeated verification.

According to the proposal of Hair and others, the ratio between the sample and the observed variable should be between 1: 10 and 1: 15, and the number of samples is from 200 to 400 (Hair 1998; Ting, 2017), in the research adopting the structural equation model as the means of analysis. And a total of 4 facets with 14 questions are included in this study, so 292 samples are used for the development model to meet the number of samples in this study. 
Table 3. The Reliability and Convergence Validity

\begin{tabular}{|c|c|c|c|c|c|c|c|c|c|c|}
\hline \multirow{2}{*}{$\begin{array}{l}\text { Latent } \\
\text { variable }\end{array}$} & \multirow[t]{2}{*}{ Questions } & \multicolumn{4}{|c|}{$\begin{array}{c}\text { Estimation of parameter } \\
\text { significance }\end{array}$} & \multirow{2}{*}{$\begin{array}{c}\begin{array}{c}\text { Factor } \\
\text { loading }\end{array} \\
\text { Std. }\end{array}$} & \multirow{2}{*}{$\begin{array}{c}\begin{array}{c}\text { Question } \\
\text { reliability }\end{array} \\
\text { SMC } \\
\end{array}$} & \multirow{2}{*}{$\begin{array}{c}\begin{array}{c}\text { Combined } \\
\text { reliability }\end{array} \\
\text { CR } \\
\end{array}$} & \multirow{2}{*}{$\begin{array}{c}\text { Convergen } \\
\text { validity }\end{array}$} & \multirow{2}{*}{$\begin{array}{c}\text { onbach's } \\
\alpha \\
\alpha \\
\end{array}$} \\
\hline & & Unstd & S.E. & t-value & $\mathbf{P}$ & & & & & \\
\hline \multirow{5}{*}{$\begin{array}{l}\text { Acceptability } \\
\text { of Recycled } \\
\text { Water }\end{array}$} & ACC1 & 1.000 & & & & .907 & .823 & .957 & .816 & .956 \\
\hline & ACC2 & 1.085 & .042 & 25.745 & $* * *$ & .917 & .841 & & & \\
\hline & ACC3 & 1.012 & .041 & 24.407 & 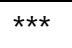 & .899 & .808 & & & \\
\hline & ACC4 & 1.010 & .041 & 24.526 & 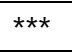 & .900 & .810 & & & \\
\hline & ACC5 & .989 & .041 & 23.992 & $* * *$ & .893 & .797 & & & \\
\hline \multirow{3}{*}{$\begin{array}{l}\text { Perceived } \\
\text { Risk of } \\
\text { Recycled } \\
\text { Water }\end{array}$} & PR1 & 1.000 & & & & .829 & .687 & .860 & .672 & .808 \\
\hline & PR2 & .987 & .071 & 13.961 & $\star \star \star *$ & .795 & .632 & & & \\
\hline & PR3 & 1.034 & .072 & 14.340 & $\star \star *$ & .834 & .696 & & & \\
\hline \multirow{3}{*}{$\begin{array}{l}\text { Knowledge } \\
\text { About } \\
\text { Recycled } \\
\text { Water } \\
\end{array}$} & KARW 1 & 1.000 & & & & .758 & .575 & .874 & .699 & .881 \\
\hline & KARW 2 & 1.210 & .083 & 14.497 & $* \star *$ & .874 & .764 & & & \\
\hline & KARW 3 & 1.216 & .084 & 14.483 & $\star * *$ & .870 & .757 & & & \\
\hline \multirow{3}{*}{$\begin{array}{l}\text { Trust in } \\
\text { Water } \\
\text { Authorities }\end{array}$} & TIWA 1 & 1.000 & & & & .710 & .504 & .838 & .634 & .849 \\
\hline & TIWA 2 & 1.188 & .099 & 11.980 & $\star \star \star$ & .852 & .726 & & & \\
\hline & TIWA 3 & 1.112 & .093 & 11.975 & $\star * \star$ & .819 & .671 & & & \\
\hline
\end{tabular}

Table 4. Discriminate Validity of Policy Mechanism Model about Knowledge Popularization

\begin{tabular}{llllll}
\hline & AVE & KARW & TIWA & PR & ACC \\
\hline KARW & .699 & .836 & & & \\
\hline TIWA & .634 & .575 & .796 & & \\
\hline PR & .672 & .513 & .551 & .820 & \\
\hline ACC & .816 & .322 & .391 & .581 & .903 \\
\hline
\end{tabular}

Note: The bold number is the square root of the AVE between the corresponding facets, and the remaining values are the Pearson correlation values between the facets.

\section{Reliability and Validity Analysis}

To judge whether the reliability of the questionnaire is up to relevant standards, this part first measures Cronbach's a, which represents the reliability, and the results are shown in Table 3. All the values of Cronbach's a are beyond the standard of 0.7 , demonstrating that the questionnaire is of sound reliability. The most widespread testing items in this field, namely, convergence validity and discrimination validity are adopted. In convergence validity test, Fornell and Larcker's recommendations are followed. Therefore, the standardized factor loading, combined reliability (CR) and average variance extraction (AVE) are noticed (Fornell 1981). The standardized factor loading is greater than 0.6 , and non-standardized tests were all significant. CR values are greater than 0.7, in line with the recommended standard of Fornell and Larcker. At the same time, the AVE values are greater than or close to 0.5 , also in line with Fornell and Larcker' recommended standard. It can be concluded that the convergence validity of each area is good.

In terms of distinguishing loudness test, according to the proposal of Fornell and Larcker, it is only necessary to determine whether the square root of the AVE value corresponding to the latent variable is greater than its Pearson correlation coefficient with all other latent variables. Therefore, from Table 4, it can be seen that the dimensions of the questionnaire have better discriminant validity. 


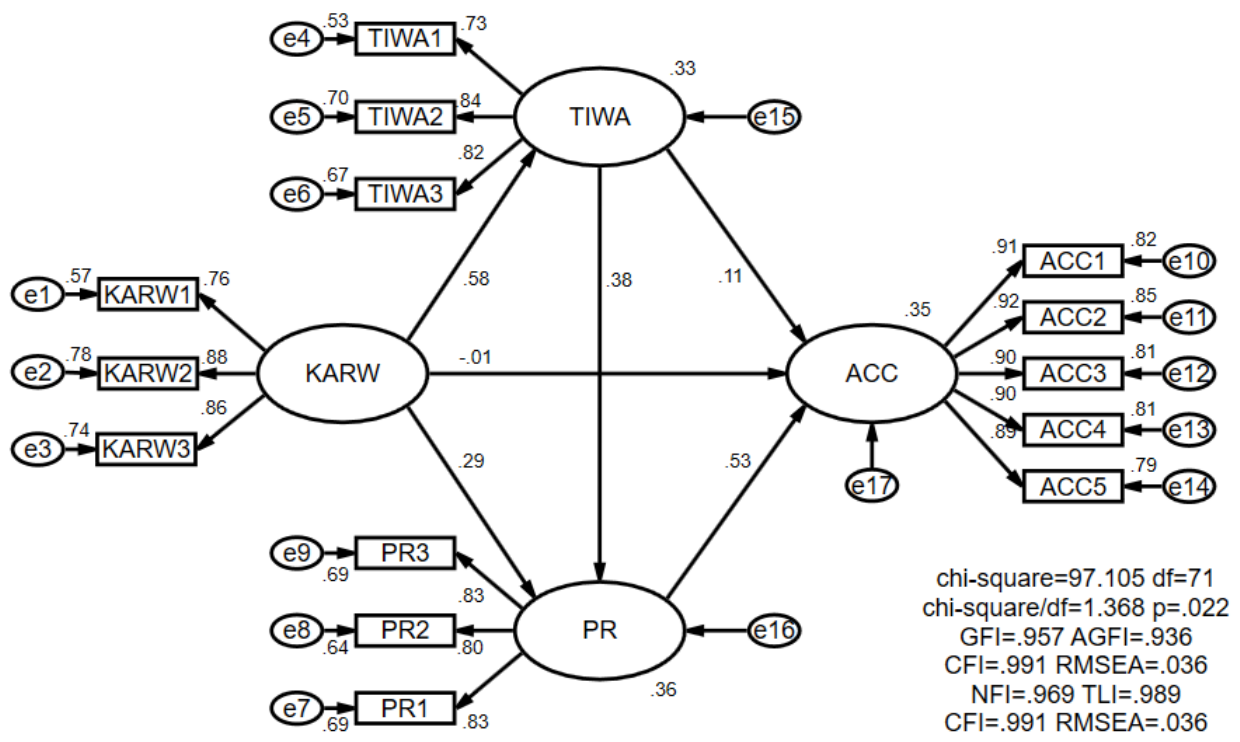

Figure 2. The standard estimation of structural equation model

Table 5. Model Fit

\begin{tabular}{lcccccccccc}
\hline Fitting indexes & Chi-square & Df & Chi-square/df & RMSEA & SRMR & GFI & AGFI & NFI & TLI & CFI \\
\hline Measured value & 97.105 & 71 & 1.368 & .036 & .033 & .957 & .936 & .969 & .989 & .991 \\
\hline
\end{tabular}

\section{Model Fit Analysis}

\section{Model fit}

After the verification of the reliability and validity of the data as well as the number of samples, in this section, with the help of AMOS21.0 software, 292 samples randomly distributed are used to develop model (see Figure 2). And then the fitting of the model is also tested. At last, another 292 samples are used to retest the developed model.

Fitting indexes are shown in Table 5.

According to Table 5, the structural equation model has good fitting indexes, indicating that the model and the data fit well.

\section{Cross-validity test}

To verify whether the structural equation model has a good cross-validity, the group comparison method is applied in this part to bring the previously randomly distributed group (292 samples) into model and compare it with the present model so as to determine whether the structural equation model has cross-group consistency(Cheung 1999). In the process, Kline's recommendation is followed and the Tight Replication Strategy is adopted to test the group consistency. The various indexes of the model are all consistent with each other, so that the structural model has cross-group consistence between the two groups. That is, the structural equation model passes the cross-validity test, and the settings of the model are correct.

\section{Model Path Coefficient Test}

Based on the verification of the structural equation model by fitting degree and cross validity, the path coefficients of the model are reported and the corresponding research hypotheses are tested. 
Table 6. Standardized Path Coefficient Test for Structural Equation Model

\begin{tabular}{ccccccc}
\hline Path name & $\begin{array}{c}\text { Standardized } \\
\text { estimated value }\end{array}$ & $\begin{array}{c}\text { Non-standardized } \\
\text { estimated value }\end{array}$ & $\begin{array}{c}\text { Standard } \\
\text { deviation }\end{array}$ & t-value & P \\
\hline $\mathrm{PR} \rightarrow \mathrm{ACC}$ & 0.528 & 0.688 & 0.101 & 6.831 & $* * *$ \\
\hline TIWA $\rightarrow \mathrm{PR}$ & 0.382 & 0.431 & 0.089 & 4.84 & $* * *$ \\
\hline TIWA $\rightarrow$ ACC & 0.107 & 0.157 & 0.115 & 1.362 & 0.173 \\
\hline KARW $\rightarrow$ PR & 0.293 & 0.242 & 0.063 & 3.867 & $* *$ \\
\hline KARW $\rightarrow$ TIWA & 0.575 & 0.422 & 0.049 & 8.693 & $* * *$ \\
\hline KARW $\rightarrow$ ACC & -0.011 & -0.012 & 0.079 & -0.15 & 0.881 \\
\hline
\end{tabular}

Table 7. The Mediational effect Test for Knowledge about Recycled Water Reuse on Acceptance of Recycled Water Reuse

\begin{tabular}{|c|c|c|c|c|c|c|c|}
\hline \multirow{3}{*}{ Indirect Effect } & \multirow{3}{*}{ Point Estimate } & \multirow{2}{*}{\multicolumn{2}{|c|}{ Product of Coefficients }} & \multicolumn{4}{|c|}{ Bootstrapping } \\
\hline & & & & \multicolumn{2}{|c|}{ BC $95 \% \mathrm{Cl}$} & \multicolumn{2}{|c|}{ Percentile $95 \% \mathrm{CI}$} \\
\hline & & SE & $\mathbf{Z}$ & Lower & Upper & Lower & Upper \\
\hline \multicolumn{8}{|c|}{ Indirect effects } \\
\hline PR & .167 & .053 & 3.151 & .080 & .294 & .075 & .284 \\
\hline TIWA & .066 & .059 & 1.119 & -.052 & .182 & -.052 & .182 \\
\hline TIWA \&PR & .125 & .037 & 3.378 & .068 & .221 & .063 & .209 \\
\hline TOTAL & .358 & .069 & 5.188 & .232 & .509 & .230 & .505 \\
\hline
\end{tabular}

Note: $\mathrm{BC}$ is short for being Bias-corrected; $\mathrm{Cl}$ stands for Confidence Interval; PR refers to path KARW $\rightarrow$ PR $\rightarrow$ ACC; TIWA refers to path KARW $\rightarrow$ TIWA $\rightarrow$ ACC; TIWA \& PR refers to path KARW $\rightarrow$ TIWA $\rightarrow$ PR $\rightarrow$ ACC; samples are obtained after 5000 times by Bootstrap.

From Table 6, the path coefficients in the structural equation model are significant except for the TIWA $\rightarrow$ ACC and KARW $\rightarrow$ ACC paths. That is, in addition to that the trust degree in the water authorities and knowledge of the recycled water reuse do not sharply affect the acceptance of recycled water, significant influences exist among other dimensions.

\section{Mediational Effect Test for Structural Equation Model}

According to the hypothesis, the consequences awareness of water pollution may affect acceptance of recycled water reuse by these three paths, namely: KARW $\rightarrow$ PR $\rightarrow$ ACC, KARW $\rightarrow$ TIWA $\rightarrow$ ACC and KARW $\rightarrow$ TIWA $\rightarrow$ PR $\rightarrow$ ACC. Whether mediational effects exist on the three paths will be tested with the Bootstrap method as follows.

From Table 7, the $\mathrm{Z}$ values of the paths $\mathrm{KARW} \rightarrow \mathrm{PR} \rightarrow \mathrm{ACC}$ and KARW $\rightarrow$ TIWA $\rightarrow$ PR $\rightarrow$ ACC are both greater than 1.96, which shows that the mediational effect of the two paths is significant with the coefficient product method. At the same time, in the Bootstrap method the minimum and maximum interval of Bias-corrected method and Percentile method does not contain 0. It is known that in the paths of the KARW $\rightarrow$ PR $\rightarrow$ ACC and KARW $\rightarrow$ TIWA $\rightarrow$ PR $\rightarrow$ ACC mediational effects are significant. Meanwhile, the path KARW $\rightarrow$ TIWA $\rightarrow$ ACC fails in the coefficient product method ( $\mathrm{Z}$ value is less than 1.96), Bias-corrected method and Percentile method (the minimum and maximum interval contains 0 ), indicating that the path of the mediational effect does not exist. It can be proved that hypothesis 2 and hypothesis 3 are established, and hypothesis 1 is invalid.

\section{CONCLUSION}

Residents' trust degree in water authorities can be improved and their risk perception for recycled water reuse can be reduced through knowledge popularization about recycled water reuse As a result, residents' 


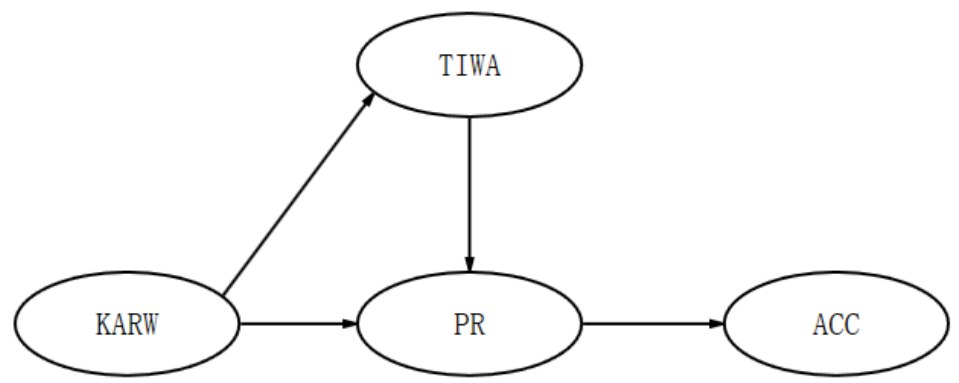

Figure 3. The Effect Path of Environmental Education on Residents' Willingness to Accept Recycled Water Reuse

behaviors about recycled water reuse can be guided. Through the examination of the path coefficient in the model and the mediational effect test, it is found that improving residents' knowledge about recycled water reuse can positively affect their willingness to accept recycled water reuse through these two influence paths. That is, reducing residents' risk perception for recycled water reuse contributes to improving the willingness to accept it; and increasing the trust degree in the water authorities is indirectly beneficial for reducing their risk perception for recycled water reuse and then enhancing their willingness to accept it. Thus the guidance of environmental education on the residents' behaviors concerning recycled water reuse and its acting path are verified, as shown in Figure 3.

On the basis of the research, the following specific suggestions are put forward in order to effectively guide residents' participating behaviors in recycled water reuse.

The first point is that environmental education is strengthened and urban residents should be stimulated to protect water environment. It has been verified that environmental motivation is conducive to guiding residents behaviors in regard to recycled water reuse in this paper. The mechanism of environmental motivation is also refined in the fifth chapter, including responsibility attribution for human activities and for water environment pollution, as well as consequences awareness of water environment pollution. In the conclusion part, it is found that residents can be effectively guided to participate in recycled water reuse by means of strengthening environmental education and raising their sense of responsibility and consequences awareness of water shortage and water pollution caused by human activities.

Moreover, relevant knowledge popularization about recycled water reuse is reinforced and public knowledge of recycled water reuse is improved. In this era of information explosion when flow means money, it is not easy to make the message about recycled water reuse to get on the ground floor in the battle for people's cognitive resources. Therefore, the author believes that related knowledge about recycled water reuse should be considered into pre-school education in order to improve residents' related knowledge. Children are supposed to be steered into building up scientific and correct understanding of recycled water reuse through proper education before their prejudices against it are not formed.

\section{ACKNOWLEDGEMENTS}

I would like to express my gratitude to all those who have helped me during the writing of this thesis.

\section{REFERENCES}

Bentler, P. M., \& Bonett, D. G. (1980). Significance tests and goodness of fit in the analysis of covariance structures. Psychological Bulletin, 88(3), 588-606. doi:10.1037/0033-2909.88.3.588

Bogardi, J. J., Dudgeon, D., Lawford, R., Flinkerbusch, E., Meyn, A., Pahl-Wostl, C., Vielhauer, K., \& Vörösmarty, C. (2012). Water security for a planet under pressure: interconnected challenges of a changing world call for sustainable solutions. Current Opinion in Environmental Sustainability, 4(1), 35-43. doi:10.1016/j.cosust.2011.12.002 
Chen, W., Bai, Y., Zhang, W., \& Jiao, W. (2015). Perceptions of different stakeholders on reclaimed water reuse: the case of beijing, china. Sustainability, 7(7), 9696-9710. doi:10.3390/su7079696

Chen, Y. (2017). Empirical Study on the Effect of Digital Game-Based Instruction on Students' Learning Motivation and Achievement. Eurasia Journal of Mathematics Science and Technology Education, 13(7)3177-3187. doi:10.12973/eurasia.2017.00711a

Cheung, G. W., \& Rensvold, R. B. (1999). Testing factorial invariance across groups: a reconceptualization and proposed new method. Journal of Management, 25(1), 1-27. doi:10.1177/014920639902500101

Fornell, C., \& Larcker, D. F. (1981). Evaluating structural equation models with unobservable variables and measurement error. Journal of Marketing Research, 18(1), 39-50. doi:10.2307/3151312

Hair, B: J. B., Anderson, R. E., \& Black, W. C. (1998). Multivariate Data Analysis (5th Ed.). Upper Saddle River, NJ: Prentice Hall, 677-679.

Hurlimann, A. C. (2007). Is recycled water use risky? An urban Australian community's perspective. Environmentalist, 27(1), 83-94. doi:10.1007/s10669-007-9019-6

Jeffrey, P., \& Jefferson, B. (2003). Public receptivity regarding “in-house” water recycling: results from a UK survey. Water Science \& Technology Water Supply, 3(3), 109-116.

Liefländer, A. K. (2015). Effectiveness of environmental education on water: connectedness to nature, environmental attitudes and environmental knowledge. Environmental Education Research, 21(1), 145-146. doi:10.1080/13504622.2014.927831

Lin, J. (2017) A Cross-Grade Study Validating the Evolutionary Pathway of Student Mental Models in Electric Circuits. Eurasia Journal of Mathematics Science and Technology Education, 13(7) 3099-3137. doi:10.12973/eurasia.2017.00707a

Otway, H. J., \& Winterfeldt, D. V. (1982). Beyond acceptable risk: on the social acceptability of technologies. Policy Sciences, 14(3), 247-256. doi:10.1007/BF00136399

Pahl-Wostl, C., Vörösmarty, C., Bhaduri, A., Bogardi, J., Rockström, J., \& Alcamo, J. (2013). Towards a sustainable water future: shaping the next decade of global water research. Current Opinion in Environmental Sustainability, 5(6), 708-714. doi:10.1016/j.cosust.2013.10.012

Roczen, N., Kaiser, F. G., Bogner, F. X., Wilson, M. (2016). A competence model for environmental education. Environment \& Behavior, 46(8), 972-992. doi:10.1177/0013916513492416

Ross, V. L., Fielding, K. S., Louis, W. R. (2014). Social trust, risk perceptions and public acceptance of recycled water: testing a social-psychological model. Journal of Environmental Management, 137(4), 61-68. doi:10.1016/j.jenvman.2014.01.039

Rozin, P., Haddad, B., Nemeroff, C., \& Slovic, P. (2015). Psychological aspects of the rejection of recycled water: Contamination, purification and disgust. Judgment $\mathcal{E}$ Decision Making, 10, 50-63.

Siegrist, M., Cvetkovich, G., Roth, C. (2010). Salient value similarity, social trust, and risk/benefit perception. Risk Analysis, 20(3), 353-362. doi:10.1111/0272-4332.203034.

Teksoz, G., \& Sahin, E. (2012). Modeling environmental literacy of university students. Journal of Science Education E Technology, 21(1), 157-166. doi:10.1007/s10956-011-9294-3

Ting, M. Y. (2017). Definite Integral Automatic Analysis Mechanism Research and Development Using the "Find the Area by Integration" Unit as an Example. Eurasia Journal of Mathematics Science and Technology Education, 13(7), 2883-2896. doi:10.12973/eurasia.2017.00724a

\section{http://www.ejmste.com}

